\title{
Educação Física e produção discente em um contexto de iniciação à docência
}

\author{
Mariana Gatto Lemos de Souza dos Santos ${ }^{1}$ \\ Gabriel de Sousa Vandelli Carneiro ${ }^{2}$ \\ Tatiany Margarido dos Santos ${ }^{3}$ \\ Lorenna Andrade Sampaio ${ }^{4}$ \\ Danielle Machado Vasconcellos ${ }^{5}$ \\ Renato Sarti ${ }^{6}$
}

\begin{abstract}
Resumo:
Dentro do contexto formativo e pedagógico do subprojeto de Educação Física do Programa Institucional de Bolsas de Iniciação à Docência (PIBID), o presente relato de experiência tem como objetivo central apresentar a produção dos educandos do ensino médio na problematização da disciplina de Educação Física. Para subsidiar as discussões, o relato mobiliza conceitos de "terceiro espaço" (ZEICHNER, 2010) e de "dialogicidade" (FREIRE, 1987), fundamentando as interlocuções entre o curso de formação de professores e os espaços escolares e propondo o ponto de partida principal para a referida proposta pedagógica. Assim, o relato conta com a descrição do cenário formativo/ pedagógico, com a apresentação de alguns componentes da tematização e, principalmente, com a valorização dos conhecimentos construídos pelos educandos na fase da problematização, por meio do detalhamento de algumas produções dos Grupos Temáticos de Trabalho (GTT). Em linhas gerais, destacaram-se três aspectos centrais na produção dos educandos: a apropriação dos conteúdos da tematização; o reconhecimento dos educandos como produtores de conhecimento; e a multiplicidade de temas e formatos dos trabalhos apresentados.
\end{abstract}

\section{Palavras-chave:}

PIBID. Educação Física. Produção do educando.

\footnotetext{
1 Graduanda de licenciatura em Educação Física pela Universidade Federal do Rio de Janeiro; Ex-bolsista de iniciação à docência do subprojeto Educação Física PIBID/UFRJ. E-mail: marianagatto08@gmail.com ORCID iD: https://orcid.org/0000-0002-2376-8229 2 Graduando de Licenciatura em Educação Física pela Universidade Federal do Rio de Janeiro; Ex-bolsista de iniciação à docência do subprojeto Educação Física PIBID/UFRJ. E-mail: gvandelli13@gmail.com ORCID iD: https://orcid.org/0000-0002-3535-1287 3 Graduanda de licenciatura em Educação Física pela Universidade Federal do Rio de Janeiro; Ex-bolsista de iniciação à docência do subprojeto Educação Física PIBID/UFRJ. E-mail: tatiany.margarido@gmail.com ORCID iD: https://orcid.org/0000-0001-7475-6810 4 Graduanda de licenciatura em Educação Física pela Universidade Federal do Rio de Janeiro; Ex-bolsista de iniciação à docência do subprojeto Educação Física PIBID/UFRJ. E-mail: lolosampaio1998@gmail.com ORCID iD: https://orcid.org/0000-0002-5502-5964 5 Graduanda de licenciatura em Educação Física pela Universidade Federal do Rio de Janeiro; Ex-bolsista de iniciação à docência do subprojeto Educação Física PIBID/UFRJ. E-mail: daniellevasconcellos@yahoo.com ORCID iD: https://orcid.org/0000-00019756-773X

6 Doutorando em Educação em Ciências e Saúde, Universidade Federal do Rio de Janeiro; Coordenador do Subprojeto Educação Física do PIBID/UFRJ. E-mail: renatosarti.eefd@gmail.com ORCID iD: https://orcid.org/0000-0001-7553-4275
} 


\section{Physical Education and student production in a teaching initiation context}

\section{Abstract:}

Within the formative and pedagogical context of the Physical Education subproject of the Programa Institucional de Bolsas de Iniciação à Docência (PIBID), this experience report has as its main objective to present the production of high school students in the problematization of the Physical Education discipline. To support the discussions, the report mobilizes concepts of "third space" (ZEICHNER, 2010) and "dialogicity" (FREIRE, 1987), supporting the dialogue between the teacher training course and school spaces and proposing the starting point for the aforementioned pedagogical proposal. Thus, the report relies on the description of the formative/pedagogical scenario, with the presentation of some components of thematization and, mainly, with the appreciation of the knowledge built by the students in the problematization phase, through the detailing of some productions of the Thematic Groups of Work (GTT). In general terms, three central aspects in the student production were highlighted: the appropriation of thematic contents; the recognition of students as knowledge producers; and the multiplicity of themes and formats of the works presented.

\section{Keywords:}

PIBID. Physical Education. Student production.

\section{Educación Física y producción estudiantil en un contexto de iniciación docente}

\section{Resumen:}

En el contexto formativo y pedagógico del subproyecto de Educación Física del Programa Institucional de Bolsas de Iniciação à Docência (PIBID), este relato de experiencia tiene como principal objetivo presentar la producción de los estudiantes de secundaria en la problematización de la disciplina de Educación Física. Para apoyar las discusiones, el informe moviliza conceptos de "tercer espacio" (ZEICHNER, 2010) y "dialogicidad" (FREIRE, 1987), apoyando el diálogo entre el curso de formación docente y los espacios escolares y proponiendo el punto de partida para la propuesta pedagógica antes mencionada. . Así, el informe se apoya en la descripción del escenario formativo / pedagógico, con la presentación de algunos componentes de la tematización y, principalmente, con la apreciación de los conocimientos construidos por los estudiantes en la fase de problematización, a través del detalle de algunas producciones de la Grupos Temáticos de Trabajo (GTT). En términos generales, se destacaron tres aspectos centrales en la producción de los estudiantes: la apropiación de contenidos temáticos; el reconocimiento de los estudiantes como productores de conocimiento; y la multiplicidad de temas y formatos de las obras presentadas.

Palabras clave:

PIBID. Educación Física. Producción estudiantil.

\section{Introdução}

A formação de professores no Brasil tem experimentado um caminho sinuoso, partindo das Escolas Normais do século XIX, passando pelos cursos universitários do século XX e, atualmente, vem caminhando para a necessária aproximação entre Universidade/Escola. Muitos trabalhos vêm assinalando a importância de estreitamento dos sujeitos atuantes nos espaços formativos, desta- 
cando-se os professores da educação básica e os professores em formação (licenciandos bolsistas de iniciação à docência) (ZEICHNER, 2010; GATTI, 2010; NÓVOA, 2017).

Deste modo, na perspectiva de emoldurar o presente relato de experiência na educação básica, dois conceitos são fundamentais: o "terceiro espaço" (ZEICHNER, 2010) e a "dialogicidade" (FREIRE, 1987). O primeiro baliza a estrutura das ações formativas propostas, destacando-se as interlocuções entre o curso de formação e os espaços escolares. A aproximação entre a Universidade e a Escola tem sido objeto de estudo de muitas pesquisas sobre a formação de professores e Zeichner (2010) propõe a constituição de um espaço comum entre o curso de licenciatura e o cenário escolar, exemplificando algumas possibilidades para o "cruzamento de fronteiras" entre elas. Tais travessias foram exemplificadas pelo autor na possibilidade de contar com o professor da educação básica e sua produção dentro do curso de formação na Universidade, ou até mesmo na possível contratação de professores híbridos, que atuem nos dois espaços supracitados. O segundo conceito é o ponto de partida principal para a proposta pedagógica, fortalecendo a dialogicidade como essência da educação como prática de liberdade (FREIRE, 1987), afastando-se da concepção de transmissão e doação desenvolvida pela "educação bancária". Desse modo, a dialogicidade posiciona-se no ponto oposto da prescrição e da contradição educador/educando, apontando para a constituição de uma educação problematizadora.

O Programa Institucional de Bolsas de Iniciação à Docência (PIBID) é o cenário formativo e pedagógico do referido relato de experiência, que tem como objetivo central apresentar a produção dos educandos do ensino médio na problematização da disciplina de Educação Física. Assim, o presente texto conta com a descrição do contexto formativo/pedagógico, com a apresentação de alguns componentes da tematização e, principalmente, com a valorização dos conhecimentos construídos pelos educandos na fase da problematização, por meio do detalhamento de algumas produções dos Grupos Temáticos de Trabalho (GTT).

\section{O cenário formativo e pedagógico: o subprojeto Educação Física PIBID/UFRJ}

Criado em 2007, o Programa Institucional de Bolsas de Iniciação à Docência (PIBID) tem como objetivo a valorização do magistério, o fortalecimento dos cursos de formação inicial de professores e a aproximação entre licenciando e escola básica (CAPES, 2008). Com mais de dez anos de experiência, o programa tem sido objeto de reflexão e estudos de inúmeras investigações do campo da pesquisa educacional, que vêm destacando os impactos do programa nos cursos de licenciatura e, sobretudo, nos percursos formativos dos licenciandos bolsistas de iniciação à docência e professores da educação básica (CLATES; GÜNTHER, 2015; ASSIS; LOBO; GALVÃO, 2018; CAMPELO; CRUZ, 2016).

Neste sentido, como contexto de realização da experiência pedagógica em tela, o subprojeto de Educação Física PIBID/UFRJ se propõe a constituir um espaço de aproximação entre o licenciando e o cenário escolar. Dessa forma, em parceria com três escolas públicas da região metropolitana do Rio de Janeiro, o subprojeto tem como objetivo, valorizar a ação e reflexão pedagógica dos licenciandos bolsistas de iniciação à docência, fortalecendo os componentes da cultura corporal como conteúdo da Educação Física escolar, bem como os espaços de construção de conhecimento dos educandos de educação básica. Segundo Costa et al. (2019)7 , o subprojeto desenvolveu suas ações no contexto da Universidade (Seminários de Identidade e Profissão Docente, Ciclo de Debates na Roda e Encontro De Lá Pra Cá) e no contexto das escolas (Cine Cultura Corporal, Jornada de Educação

70 trabalho citado foi desenvolvido por integrantes do subprojeto e apresentou um panorama das ações desenvolvidas. São autores dois licenciandos bolsistas de iniciação à docência, um professor supervisor da educação básica e um coordenador do subprojeto. 
Física na Escola e Sequência Pedagógica). Como enfoque do presente trabalho, essa última ação, a sequência pedagógica, foi desenvolvida em três etapas: imersão, tematização e problematização.

A imersão apresentou-se como um espaço de aproximação entre a comunidade escolar e os licenciandos bolsistas de iniciação à docência. Para estes últimos, tratou-se dos primeiros contatos com o ambiente pedagógico e com os sujeitos que fazem parte dele. Na segunda etapa, a tematização, os licenciandos, os professores da educação básica e os educandos criaram cenários de vivência e reflexão sobre a cultura corporal, que tem como conteúdo: os jogos, as brincadeiras, as lutas, os esportes, as danças e as ginásticas (SOARES et al., 1992). Sobre a terceira etapa, a problematização, destaca-se o protagonismo dos educandos e a valorização de sua produção de conhecimento. Foi nesta fase que os educandos, em parceria com os licenciandos bolsistas de iniciação à docência, desenvolveram seus trabalhos. Nesta perspectiva, o presente relato de experiência tem como recorte a socialização dos resultados da fase de problematização dos educandos de uma escola pública da cidade de Duque de Caxias (RJ), bem como a realização da Jornada de Educação Física na escola. A escolha pela escola está relacionada ao espaço de atuação dos autores e licenciandos bolsistas de iniciação à docência, que, junto ao professor da educação básica, construíram a referida sequência pedagógica. Fizeram parte desta experiência duas turmas, com aproximadamente trinta educandos cada uma, que cursavam o ensino médio durante o ano de 2019.

\section{A proposta pedagógica: a imersão, a tematização e a problematização}

Primeira etapa da experiência aqui apresentada, a imersão aconteceu durante três semanas, e permitiu a ascensão de dois apontamentos importantes para as etapas subsequentes: as práticas esportivas nos intervalos das aulas e a tímida participação das meninas. Em suma, a referida etapa ofereceu a oportunidade de estabelecer uma interlocução com os educandos, suas ações e reflexões sobre a Educação Física e as suas práticas corporais. Ao encerrar a fase de imersão, o subprojeto deu início à sua segunda etapa, a tematização, que contou com sete encontros de vivência e reflexão sobre a cultura corporal, fomentando o debate sobre os temas relacionados aos jogos e brincadeiras, às lutas, aos esportes, às danças e à ginástica. Nesse sentido, a construção da tematização e a definição do conjunto de manifestações da cultura corporal abordadas nasceu da interlocução entre o programa da escola, os conceitos de memória lúdica (SOARES et al., 1992), dialogicidade (FREIRE, 1987) e a perspectiva histórica das manifestações construídas nacional e internacionalmente (Quadro 1).

Quadro 1 - Conteúdos da tematização

\begin{tabular}{|c|c|}
\hline CULTURA CORPORAL & PRÁTICAS CORPORAIS \\
\hline Jogos e Brincadeiras & $\begin{array}{c}\text { Taco; Emusi; Corrida de toras; Corda; Sinuca; Altinha; } \\
\text { Frisbee; Manbol. }\end{array}$ \\
\hline Esportes & $\begin{array}{c}\text { Aspectos históricos do Atletismo; Corridas de } \\
\text { revezamento. }\end{array}$ \\
\hline Ginásticas & $\begin{array}{c}\text { Aspectos históricos da Ginástica Artística; Os tipos de } \\
\text { saltos na GA. }\end{array}$ \\
\hline Danças & $\begin{array}{c}\text { Cultura popular; Aspectos Históricos do Frevo; Diálogos } \\
\text { com Funk carioca }\end{array}$ \\
\hline Lutas & Capoeira; Huka-Huka \\
\hline
\end{tabular}

Fonte: Elaborado pelos autores. 
Diante do universo de práticas tematizadas e os limites para o desenvolvimento deste relato, optou-se por socializar o recorte com algumas das experiências desenvolvidas no decorrer desta etapa. Com isso, ganharam um maior detalhamento os estudos e vivências realizadas com as ginásticas, as danças e as lutas.

A ginástica, uma das manifestações da cultura corporal, foi tematizada e estudada enquanto uma construção histórica, indicando que o homem não nasceu saltando e correndo, mas que estas movimentações foram construídas em determinados contextos sócio-históricos em resposta a determinadas necessidades humanas (TAFFAREL; ESCOBAR, 2009). Deste modo, os educandos foram provocados a inventariar suas referências sobre as expressões gímnicas, sendo elencadas a "ginástica aeróbica", a "ginástica rítmica", e a "ginástica artística", modalidades conhecidas, sobretudo, pela influência da mídia. Em sequência, aprofundando os conhecimentos sobre uma das manifestações citadas pelos educandos, o espaço contou com a contextualização do surgimento da ginástica artística e seu aparecimento em solo nacional. Posteriormente, foram apresentados alguns elementos da ginástica artística, como a parada de mãos, a estrela, e os saltos (esticado, grupado e afastado). Na etapa da vivência, foram introduzidos alguns destes movimentos em uma brincadeira popular, o "pedra, papel e tesoura". O salto esticado representava o papel, já o salto afastado a tesoura, e, por fim, o salto grupado, a pedra.

Ao tematizar o Frevo, explorando o significado da palavra, corruptela de "ferver" (GEHRES; BRASILEIRO, 2014), foram apresentados alguns passos, como o "saci pererê" e a "tesoura", que acompanham as movimentações das típicas sombrinhas coloridas. Na vivência, foi proposto para os educandos que se dividissem em dois grupos e usassem a criatividade para a construção de uma sequência. As apresentações foram surpreendentes e riquíssimas, contando com a interlocução dos movimentos característicos do frevo, estudados naquele dia, com os passinhos de funk já presentes na memória lúdica dos educandos.

A capoeira, manifestação de origem afro-brasileira, foi contextualizada enquanto luta de emancipação do povo negro, que expressa através do seu conjunto de movimentos, a voz do oprimido perante o opressor (SOARES et al., 1992). Na vivência, foi proposta a experimentação de alguns golpes e esquivas da capoeira em duplas, tendo assumido o protagonismo os educandos que já haviam praticado anteriormente. O huka-huka, luta originária dos povos indígenas do Xingu, consiste em uma oposição com o objetivo de deslocar o adversário, derrubando-o no chão. Foi proposto que os alunos vivenciassem diferentes tipos de oposição além do huka-huka (luta de polegares, briga de galo e sumô). Em suma, a tematização refletiu também sobre outras manifestações da cultura corporal (jogos, brincadeiras e esportes), com destaque para o atletismo, a altinha, o taco e a corrida de toras.

Mesmo compreendendo que o ato de problematizar atravessou todo o processo pedagógico, ao final dos encontros de tematização a experiência pedagógica em tela seguiu para sua última etapa metodológica, a problematização. Nesta fase, para o desenvolvimento das propostas discentes, foram construídos cinco grupos temáticos de trabalho (GTT), contemplando as diferentes manifestações da cultura corporal: jogos, esportes, lutas, dança e ginástica. Estas construções culminaram na realização da Jornada de Educação Física na Escola, que contou com a apresentação de quinze propostas de autoria dos educandos (Quadro 2). 
Quadro 2 - Jornada de Educação Física na escola: as produções dos GTTs.

\begin{tabular}{|c|c|c|c|}
\hline GTT & FORMATO & TEMA & DESCRIÇÃO \\
\hline \multirow{3}{*}{\begin{tabular}{l}
$\infty$ \\
$\stackrel{\infty}{\infty}$ \\
\hdashline
\end{tabular}} & $\begin{array}{c}\text { Mini } \\
\text { documentário }\end{array}$ & $\begin{array}{l}\text { Jogos } \\
\text { populares }\end{array}$ & $\begin{array}{l}\text { Exibição do minidocumentário com entrevistas aos educandos e } \\
\text { seus familiares sobre os jogos populares na infância. }\end{array}$ \\
\hline & Oficina & $\begin{array}{l}\text { Jogos } \\
\text { indígenas }\end{array}$ & Vivência do toloi kunhügü, jogo originário do povo Kalapalo. \\
\hline & Seminário & $\begin{array}{l}\text { Jogos } \\
\text { africanos }\end{array}$ & $\begin{array}{l}\text { Apresentação do mapa do continente africano e a origem de } \\
\text { alguns jogos. }\end{array}$ \\
\hline \multirow{5}{*}{ 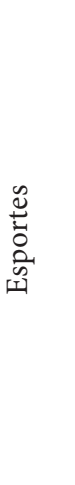 } & Demonstração & $\begin{array}{l}\text { Basquete de } \\
\text { rua }\end{array}$ & $\begin{array}{l}\text { Exibição de alguns componentes técnicos da modalidade } \\
\text { streetball. }\end{array}$ \\
\hline & $\begin{array}{c}\text { Mini } \\
\text { documentário }\end{array}$ & Futebol & $\begin{array}{l}\text { Apresentação de vídeos de gols históricos dos principais clubes } \\
\text { cariocas de futebol. }\end{array}$ \\
\hline & Seminário & $\begin{array}{l}\text { Esportes } \\
\text { eletrônicos }\end{array}$ & $\begin{array}{l}\text { Tematização sobre o surgimento dos jogos eletrônicos, com } \\
\text { destaque na regulamentação da modalidade. }\end{array}$ \\
\hline & Oficina & $\begin{array}{l}\text { Voleibol } \\
\text { sentado }\end{array}$ & $\begin{array}{c}\text { Vivência do voleibol paralímpico e reorganização do espaço/ } \\
\text { materiais. }\end{array}$ \\
\hline & Seminário & $\begin{array}{l}\text { Basquete } \\
\text { feminino }\end{array}$ & $\begin{array}{c}\text { Apresentação de retomada histórica da participação feminina no } \\
\text { basquete olímpico. }\end{array}$ \\
\hline \multirow{3}{*}{$\stackrel{\overbrace{}}{\leftrightarrows}$} & Demonstração & Capoeira & Apresentação de alguns golpes e esquivas da capoeira. \\
\hline & Demonstração & Jiu-Jitsu & Exibição de alguns golpes da modalidade brasileira. \\
\hline & Demonstração & Luta olímpica & Apresentação de um golpe relacionado à luta olímpica. \\
\hline \multirow{3}{*}{ 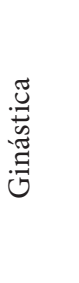 } & $\begin{array}{l}\text { Mini documen- } \\
\text { tário/ oficina }\end{array}$ & $\begin{array}{l}\text { Ginástica } \\
\text { aeróbica }\end{array}$ & $\begin{array}{l}\text { Exibição de vídeos da década de } 1980 \text { e experimentação desta } \\
\text { manifestação gímnica. }\end{array}$ \\
\hline & Oficina & Yoga & $\begin{array}{l}\text { Vivência de algumas posturas básicas e debate sobre saúde } \\
\text { mental. }\end{array}$ \\
\hline & Oficina & Parkour & $\begin{array}{l}\text { Montagem de um circuito para a vivência coletiva desta prática } \\
\text { corporal. }\end{array}$ \\
\hline 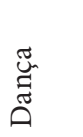 & Seminário & $\begin{array}{l}\text { Funk, Samba } \\
\text { e Rap }\end{array}$ & $\begin{array}{l}\text { Debate sobre a criminalização dos estilos musicais periféricos a } \\
\text { partir da apresentação de letras de funk, samba e rap. }\end{array}$ \\
\hline
\end{tabular}

Fonte: Elaborado pelos autores.

A Jornada de Educação Física na Escola aconteceu no dia 18 de novembro de 2019, contando com a participação de todos os educandos envolvidos no subprojeto. Cabe destacar que o presente relato detalha algumas das produções dos GTTs. Esta escolha pelo recorte na apresentação dos trabalhos da jornada está condicionada ao espaço limitado para o desenvolvimento dos quinze trabalhos.

As produções do GTT Jogos apresentaram uma valorização da referida manifestação enquanto uma construção histórica de ocorrência local, nacional e universal. Neste sentido, em um dos trabalhos, a temática de jogos populares foi desenvolvida a partir da construção de um documentário baseado no resgate da memória lúdica dos educandos e de seus familiares, representando a valorização da cultura local. Questões como "o que você brincava na rua durante a infância?" e "compare os jogos da sua época com os jogos atuais" direcionaram o documentário e assinalaram 
a redução de jogos e brincadeiras nas ruas em torno da escola, ora pela violência urbana, ora pelo tráfego de carros, como apontaram os entrevistados.

Em outra produção, em formato de oficina, a temática de jogos indígenas caminhou para a valorização das manifestações culturais em nível nacional ao contextualizar o toloi kunhügü, jogo originário do povo Kalapalo, da região sul do Parque Indígena do Xingu, no Mato Grosso. Após descrever o contexto de sua criação, bem como as regras e objetivos do jogo, o grupo provocou a turma a inventariar suas referências sobre jogos com características semelhantes ao toloi kunhügü. Por outro lado, a temática de jogos africanos sublinhou o interesse dos educandos pelas construções históricas de âmbito internacional. O grupo reconstruiu o mapa do continente africano, apontando para os países que foram cenário para a criação de alguns jogos, como "saltando o feijão", "terra-mar" e "acompanhe meus pés" (Figura 1).

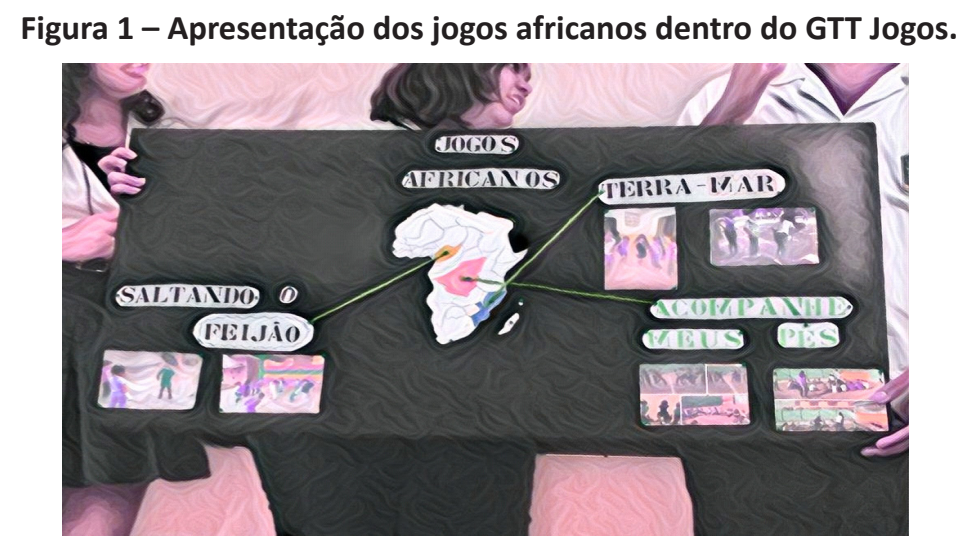

Fonte: Elaborada pelos autores

O GTT Esportes contou com cinco produções que seguiram, sobretudo, para o debate sobre a inclusão enquanto um conceito amplo no âmbito esportivo, abrangendo a todas as pessoas (FONSECA; RAMOS, 2017). Nesse sentido, a temática do basquetebol foi apresentada sob duas roupagens: o basquete de rua ou streetball, e o basquete feminino, destacando grupos sociais que historicamente têm sido excluídos. O grupo responsável pela temática do basquete de rua apontou para o seu surgimento enquanto prática informal do tradicional esporte em espaços públicos nos guetos nova-iorquinos na década de 70. A modalidade que carrega em si grande influência do movimento negro da época, principalmente do hip-hop, diferencia-se do basquete tradicional a partir da secundarização da cesta. No streetball o mais importante é a realização de movimentos que deixem o adversário desconcertado, como dribles e malabarismos com a bola e com forte presença do gingado do break (SILVA, 2012; CANAN; SILVA, 2013). Após a contextualização inicial, o grupo partiu para a demonstração de alguns dos movimentos característicos do basquete de rua.

A temática do voleibol sentado, ou voleibol paralímpico, foi apresentada como um caminho para a inclusão de pessoas com alguma deficiência física ou relacionada à locomoção (COMITÊ PARALÍMPICO BRASILEIRO, 2020). O grupo contextualizou seu surgimento enquanto uma hibridação do voleibol tradicional com o sitzball ${ }^{8}$, incluída nos Jogos Paralímpicos em 1980 sob duas categorias, sentado e em pé (CARVALHO; ARAÚJO; GORLA, 2013). Ao final da contextualização e da exposição das regras e objetivos do jogo, o grupo propôs a vivência do voleibol paralímpico

8 Jogo de origem alemã cujo objetivo é fazer com que a bola toque o solo na quadra adversária. A modalidade é realizada entre duas equipes em que os jogadores se posicionam sentados no chão e não possui rede separando-as (CARVALHO; ARAÚJO; GORLA, 2013). 
nas configurações que a modalidade assumiu desde 2004, disputada apenas com participantes sentados (Figura 2).

Figura 2 - Vivência do voleibol sentado dentro do GTT Esportes.

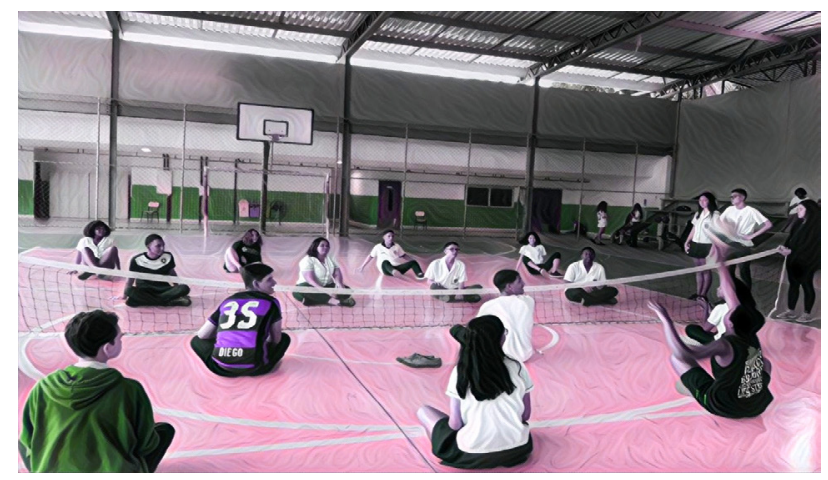

Fonte: Elaborada pelos autores.

O GTT Lutas favoreceu o debate sobre a valorização da manifestação corporal em questão enquanto uma construção histórica de ampla ocorrência, desde local até internacional, colocando em debate as práticas corporais capoeira, jiu-jitsu e luta olímpica. Neste sentido, a temática da capoeira, apresentada a partir da demonstração de alguns golpes e esquivas, abriu a discussão do grupo temático posicionando-a como uma luta de origem afro-brasileira marcada por movimentos de resistência.

O GTT Ginástica contou com três propostas distintas que encaminharam, principalmente, o debate sobre saúde e seus desdobramentos: ginástica aeróbica, yoga e parkour. Assim, o grupo responsável pelo tema da ginástica aeróbica apresentou a modalidade a partir da exposição de um vídeo com montagem de autoria própria, contendo cenas de filmes e programas televisivos da década de 80 que colocavam a referida modalidade como atividade para promoção de saúde. Após a exposição do material, o grupo iniciou a discussão sobre este conceito de saúde e seu envolvimento com os padrões estéticos impostos, tendo em vista que as cenas, em geral, eram protagonizadas por mulheres magras. Como segunda produção do GTT Ginástica, o yoga apresentou-se enquanto uma temática rica para o debate sobre a saúde mental. Após a discussão sobre o conceito de saúde de acordo com a Organização Mundial de Saúde e a potencialidade do yoga enquanto prática integrativa que busca romper a dualidade corpo/mente, o grupo propôs a vivência de algumas das posturas clássicas do yoga, como o uttanasana (postura do alongamento intenso) e utthita parsvakonasana (postura do ângulo lateral estendido).

O GTT Dança contou com uma produção apoiada em três estilos musicais (funk, samba e rap) e levantou questões sobre discriminação, desvalorização e, principalmente, criminalização destas manifestações corporais. Dentro do seminário de apresentação do grupo foi realizada a escuta reflexiva de algumas músicas e, em seguida, realizada uma problematização por meio de uma enquete proposta para os participantes da Jornada, na tentativa de delinear esta referida criminalização: "Você acha que o funk está associado ao crime? Por quê?" e "Você acha que a religião implica na preferência do estilo musical do indivíduo?". Em suma, o espaço apresentou uma riqueza na reflexão e um aquecido debate de concepções sobre estas manifestações.

\section{Considerações finais}

Diante de uma tematização preocupada com a valorização das diversas manifestações da cultura corporal, foi possível assinalar três aspectos centrais na produção dos educandos, dentro dos GTTs e na etapa de problematização: a apropriação dos conteúdos da tematização por parte dos 
educandos; o reconhecimento dos educandos como produtores de conhecimento; e a multiplicidade de temas e formatos dos trabalhos apresentados. Sobre a apropriação dos educandos, destacam-se as interlocuções entre os conteúdos da tematização e as questões do cotidiano, possibilitando a emergência de temas enraizados e questões relevantes dentro da realidade vivida em comunidade. Assim, os educandos, licenciandos bolsistas de iniciação à docência, experienciaram a constituição de um espaço de aprendizado compartilhado, dialógico e problematizador. As produções dos GTTs aproximaram o conteúdo da tematização e esta realidade vivida, com destaque para a abordagem de questões relacionadas aos jogos populares, funk e basquete de rua, manifestações corporais pertencentes à cultura corporal comunitária. O segundo aspecto relaciona-se com a valorização das produções, dos saberes dos educandos e, sobretudo, dos GTTs como um espaço de construção coletiva de conhecimento. Compostos por professor da educação básica, licenciandos bolsistas de iniciação à docência e educandos, os GTTs demonstraram a força e o protagonismo dos educandos. Ainda, como terceiro aspecto, evidenciou-se a multiplicidade das produções, tanto no que se refere às temáticas, quanto aos formatos (oficina, documentário, seminário, demonstração).

Em compêndio, as produções oriundas da referida experiência retomam os dois pontos de partida, aproximando Universidade/Escola e, sobretudo, reafirmando a dialogicidade como essência da educação como prática de liberdade. Ao buscarem base na perspectiva freiriana, as escolhas pedagógicas do referido relato afastaram-se da lógica prescritiva, bancária e da contradição educador/educando.

\section{Referências}

ASSIS, Alessandra Santos; LOBO, Soraia Freaza; GALVÃO, Nelma de Cássia Silva Santos. Novos olhares sobre a docência: enfrentando o desafio para formar professores. In: ASSIS, Alessandra Santos (org.). Olhares sobre a docência: as contribuições do Pibid Ufba para a formação em rede. Salvador: EDUFBA, 2018. p. 11-34.

CAMPELO, Talita da Silva; CRUZ, Giseli Barreto. Parceria universidade-escola básica e a aprendizagem da docência: contribuições da relação entre os professores supervisores do PIBID e os licenciandos bolsistas. Formação Docente, Belo Horizonte, v. 9, n. 15, p. 95-108, ago./dez. 2016. Disponível em: https://revformacaodocente.com.br/index.php/ rbpfp/article/view/143/131. Acesso em: 16 ago. 2020.

CANAN, Felipe; SILVA, Rogério Vaz. Considerações histórico-sociológicas acerca do basquete de rua e suas possíveis relações com a educação física escolar. Caderno de Educação Física e Esporte, Marechal Cândido Rondon, v. 11, n. 1, p. 65-77, jan./jun. 2013. Disponível em: http://e-revista.unioeste.br/index.php/cadernoedfisica/article/download/8294/6463. Acesso em: 16 ago. 2020.

CAPES. Formação de Professores da Escola Básica - PIBID. Brasília, DF: CAPES, 2008. Disponível em: https://www. gov.br/capes/pt-br/acesso-a-informacao/perguntasfrequentes/formacao-de-professores-da-educacao-basica. Acesso em: 16 ago. 2020.

CARVALHO, Camila Lopes; ARAÚJO, Paulo Ferreira; GORLA, José Irineu. Voleibol sentado. Conexões, Campinas, v. 11, n. 2, p. 97-126, jun. 2013. Disponível em: https://periodicos.sbu.unicamp.br/ojs/index.php/conexoes/article/ view/8637619. Acesso em: 28 jun. 2020.

CLATES, Daniela Moura; GÜNTHER, Maria Cecília. O PIBID e o percurso formativo de professores de Educação Física. Motrivivência, Florianópolis, v. 27, n. 46, p. 53-68, dez. 2015. Disponível em: https://periodicos.ufsc.br/index. php/motrivivencia/article/view/2175-8042.2015v27n46p53. Acesso em: 16 ago. 2020.

COMITÊ PARALÍMPICO BRASILEIRO (CPB). Vôlei sentado. São Paulo: CPB, 2020. Disponível em: https://www.cpb. org.br/modalidades/60/volei-sentado. Acesso em: 10 ago. 2020.

COSTA, Roberto Martins; FREIRE, Carina; SANTOS, Tatiany Margarido; SARTI, Renato. Ensino de Educação Física: entre a cultura corporal e a produção discente. In: CONGRESSO BRASILEIRO DE CIÊNCIAS DO ESPORTE, 21., 2019, Natal. Anais [...]. Natal: UFRN, 2019. Disponível em: http://www.cbce.org.br/anais.php. Acesso em: 18 abr. 2020. 
ESCOBAR, Michele Ortega; TAFFAREL, Celli Nelza Zülk. Cultura Corporal e os Dualismos Necessários à Ordem do Capital. Boletim Germinal, Londrina, n. 9, 2009.

FONSECA, Michele Pereira; RAMOS, Maitê Mello Russo. Inclusão em movimento: discutindo a diversidade nas aulas de educação física escolar. In: PONTES JR, José Airton de Freitas (org.). Conhecimentos do professor de educação física escolar [livro eletrônico]. Fortaleza: EdUECE, 2017. p. 184-208.

FREIRE, Paulo. Pedagogia do Oprimido. 17. ed. Rio de Janeiro: Paz e Terra, 1987.

GATTI, Bernadete Angelina. Formação de Professores no Brasil: características e problemas. Educação e Sociedade, Campinas, v. 31, n. 113, p. 1355-1379, out./dez. 2010. Disponível em: https://www.scielo.br/pdf/es/v31n113/16.pdf?origin=publication_detail. Acesso em: 07 jul. 2020.

GEHRES, Adriana de Faria; BRASILEIRO, Lívia Tenório. Frevo/passo: uma alegria urbana e tensa: como ensinar? Pensar a Prática, Goiânia, v. 17, n. 4, out./dez. 2014. Disponível em: https://www.revistas.ufg.br/fef/article/view/30306/17761. Acesso em: 10 ago. 2020.

NÓVOA, Antônio Sampaio. Firmar a posição como professor, afirmar a profissão docente. Cadernos de Pesquisa, São Paulo, v. 47, n. 166, p. 1106-1133, out./dez. 2017. Disponível em: https://www.scielo.br/pdf/cp/v47n166/1980-5314-cp-47-166-1106. pdf. Acesso em: 07 jul. 2020.

SILVA, Bianca das Neves. O streetball trazendo o hip hop para a escola. In: COLÓQUIO INTERNACIONAL CULTURAS JOVENS AFRO-BRASIL AMÉRICA: ENCONTROS E DESENCONTROS, 1., 2012, São Paulo. Anais [...]. São Paulo: USP, 2012. Disponível em: http://www.proceedings.scielo.br/pdf/cjaba/n1/04.pdf. Acesso em: 12 ago. 2020.

SOARES, Carmen Lúcia; TAFFAREL, Celi Nelza Zülk; ESCOBAR, Michele Ortega; VARJAL, Elizabeth; FILHO, Lino Castellani; BRACHT, Valter. Metodologia do Ensino de Educação Física. São Paulo: Cortez, 1992.

ZEICHNER, Kenneth. Repensando as conexões entre a formação na universidade e as experiências de campo na formação de professores em faculdades e universidade. Educação, Santa Maria, v. 35, n. 3, p. 479-504, set./dez. 2010. Disponível em: https://periodicos.ufsm.br/reveducacao/article/view/2357/1424. Acesso em: 07 jul. 2020.

Data de submissão: 16/08/2020

Data de aceite: $31 / 12 / 2020$ 